\title{
AS IRMANDADES NEGRAS: “LOCUS" DE RELIGIOSIDADE POPULAR
}

Vera Irene Jurkevics*

\section{Resumo}

Nesse artigo abordamos uma das muitas manifestações de fé e, por isso procuramos, num primeiro momento, contrapor as várias dimensões da religiosidade popular a partir do entendimento diferenciado entre estudiosos e especialistas, e representantes do discurso oficial da Igreja. Nesse contexto, as irmandades negras ganham destaque nesta reflexão, como forma de vivência religiosa e sobrevivência de traços identificatórios, assim como a conquista de um tempo e de um espaço sagrado, negociados por meio das brechas institucionais no contexto da ordem escravocrata colonial. Através dessas confrarias, os "irmãos" reelaboravam, em parte, seu mundo, sobretudo durante a organização e a realização de suas festas devocionais, momentos em que conseguiam transcender - mesmo que temporariamente - sua condição de excluídos sociais.

Palavras-chave: Irmandades, religiosidade popular, devoções, santos padroeiros.

\section{REFLEXÃO CONCEITUAL}

O mês de novembro foi institucionalizado como o da consciência negra brasileira. Nesse período se celebra, por meio de múltiplos eventos e

* Mestre em História pela Universidade Estadual Paulista Júlio de Mesquita Filho e doutora em História pela Universidade Federal do Paraná. Professora do Departamento Acadêmico de Estudos Sociais da Universidade Tecnológica Federal do Paraná e da Faculdade Dr. Leocádio José Correia. (verairene@terra.com.br) 
publicações, as mais variadas participações dos afro-descendentes na construção histórica da cultura brasileira.

Nesse sentido, nossa contribuição se refere às práticas religiosas das populações negras escravizadas ou forras que, como todo o restante de suas vidas, situava-se à margem do restante da sociedade.

Como esclarecimento para o encaminhamento de nossas questões, queremos ressaltar que as investigações, no campo da História das Religiões, realizadas a partir do século XX, romperam de forma acentuada, em termos de reflexão e saber, com o monopólio antes exercido pelas teologias e pela História da Igreja e têm enfrentado, desde então, o desafio de apontar as rupturas e/ou as permanênciàs no universo" do sagrado.

Nessa perspectiva, muitos historiadores, cientistas sociais e antropólogos, superando as tradicionais abordagens das doutrinas e dos dogmas e preterindo os discursos oficiais, saíram em busca de outras trilhas, sobretudo aquelas que se distanciam das ortodoxias, identificadas genericamente como religiosidades populares, procurando desvendar 0 significado de diferentes práticas de culto e de suas formas devocionais.

É precisamente esta a nossa escolha. Para tanto, buscamos suporte para possíveis definições de "popular".

Peter Burke (1989), preocupado com essa questão, em seu trabalho acerca de cultura popular na Idade Moderna, discute, de início, os dois conceitos, "popular" e "elite", separadamente, mas recusa uma concepção polarizada entre eles. Diz ele

A fronteira entre as várias culturas do povo e as culturas das elites (e estas eram tão variadas quanto aquelas) é vaga e por isso a atenção dos estudiosos do assunto deveria concentrarse na interação e não na divisão entre elas (...) biculturalidade das elites, suas tentativas de 'reformar' a cultura popular, sua 'retirada' delas e finalmente sua 'descoberta', ou mais exatamente 'redescoberta' da cultura do povo (1989, p. 21).

Tais reflexões apontam para a modificação do sentido da palavra 'povo' usada, de modo geral, para designar 'todo mundo' ou 'gente respeitável', e 
que, posteriormente ganhou uma nova dimensão: 'a gente simples'. Posto desta forma, não é difícil percebemos, a necessidade de se precisar, as expressões em uso neste trabalho, envolvendo as manifestações populares de fé, sobretudo quando a Igreja, de um lado, e estudiosos e especialistas, de outro, utilizam-se do mesmo termo - religiosidade popular - porém com entendimentos diferenciados quanto ao seu significado.

Nesta trilha, Georges Duby (1986) propôs que se refletisse acerca do que o Cristianismo do século XIV recebeu das atitudes religiosas espontâneas do povo, no momento em que, sob a influência dos pregadores dominicanos e franciscanos, os dirigentes da Igreja quiseram colocar-se ao alcance das massas. O autor aponta que, naquele momento, o clero teve que tomar de empréstimo certo número de temas e representações da cultura popular e misturá-los a um conjunto ideológico. No entanto, esta apropriação de elementos da espiritualidade das massas, baseada essencialmente em práticas comunitárias, permaneceu em suas formas de expressão, puramente aristocráticas.

Michel Vovelle (1987), de forma semelhante, reconhece que, numerosos estudos acerca de temas culturais, delineam com freqüência uma dicotomia entre a cultura de elite, de um lado, e a cultura popular, de outro, sendo a hegemônica considerada dinâmica e versátil, enquanto a outra, quase sempre, é vista como conservadora de uma herança de longa duração, evoluindo segundo um ritmo próprio. O historiador enfatiza que, em geral, os estudos têm apontado para um confronto entre os diferentes níveis de cultura e que, por isso, é necessário romper esse diálogo estéril entre cultura popular e cultura de elite para que se produza uma leitura muito mais dinâmica. Assim, Vovelle sugere que as análises sejam feitas a partir de trocas recíprocas, o que, em boa parte, sustentam nossas análises pessoais.

Vale lembrar ainda que a dicotomização entre cultura popular e cultura erudita, vem sendo, a partir de Mikhail Bakthin (1987) e de Carlo Ginzburg, reiteradamente negada pelos historiadores da cultura. Nesse sentido, Roger Chartier afirma que

Deixou de ser sustentável estabelecer correspondências estritas entre clivagens culturais e hierarquias sociais, relacionamentos simples entre 
objetos ou formas culturais particulares e grupos sociais específicos. Não parece ser possível identificar a absoluta diferença e a radical especificidade da cultura popular a partir de textos, de crenças de códigos que Ihe seriam próprios. Todos os materiais, portadores de práticas e dos pensamentos da maioria são sempre mistos, combinando formar e motivos, invenções e tradições, cultura letrada e base folclórica. A posição macroscópica entre popular e letrado, perdeu a sua pertinência (1994, p. 121).

Todas estas reflexões acerca da cultura e sobre sua dinâmica entre os diferentes extratos sociais, desdobram-se para as questões das relações dos homens com o divino e as muitas experiências que têm, tanto em termos individuais, como coletivamente, com o sagrado.

Os questionamentos propostos por estes especialistas, apontados até agora demonstram a necessidade de, na esfera religiosa, se divisar que, por detrás das unidades aparentes, de conjuntos de dogmas, de crenças e de ritos diversos, encontra-se um pluralismo de vivências que se completam e ora, transparecem conflito e tensão.

Nesse sentido recorremos às proposições de Luiz Maldonado que ressaltou uma distinção entre o popular e o não popular, que transcende as simplificações tradicionais como laico/clerical, institucionalizado/ desclericalizado ou ainda, popular/erudito. Este autor se opõe ao argumento de que a religiosidade popular pudesse se configurar como "a busca de relações mais simples, mais direta e rentável com o Divino” (1986, p. 401).

Para ele não existe essa intencionalidade, mesmo porque advoga um caráter acentuadamente emocional, portanto espontâneo, onde não caberia, essa racionalidade em busca do mais simples, do mais direto e do mais rentável.

Numa análise mais ampla, mas igualmente inclinada ao aspecto da emotividade das manifestações piedosas e devocionais, o trabalho de Cristian Parker (1996) contempla o universo das religiosidades populares na América Latina, desde a conquista até a atualidade. Para ele, a religião desempenhou um papel fundamental na conformação das culturas nacionais, especialmente no processo de estruturação das culturas populares e, é para este tema que o autor voltou, de forma mais centralizada, a sua 
atenção. $\mathrm{O}$ autor reafirma a presença preponderante do cristianismo e mais especificadamente do catolicismo, na identidade latino-americana, sem descuidar da emergência do pluralismo cultural e religioso.

Ao final de sua análise, o autor enfatiza que somente uma reflexão profunda das raízes históricas e do reconhecimento das diversidades e, portanto de diferentes identidades, permitem uma avaliação honesta e profunda do universo religioso dos diferentes povos.

Tomando de empréstimos os caminhos já trilhados por esses estudiosos, iniciamos efetivamente nossa análise acerca de uma das muitas manifestações de fé popular: as irmandades negras.

\section{RELIGIOSIDADES POPULARES}

A implantação do catolicismo no Brasil refletiu, de um modo geral, as muitas práticas que integravam a cultura religiosa portuguesa marcada por uma tradição medieval que ainda não havia absorvido a reforma tridentina ${ }^{1}$, em curso, em boa parte na Europa. Laura de Mello e Souza (1986) aponta que, mesmo lá, demorou muito tempo até que fosse estabelecida uma uniformidade em torno das decisões conciliares, uma vez que, durante 0 século XVI, as paróquias não chegavam a ser verdadeiramente importantes na religiosidade vivida por aquelas populações e que, no século seguinte, duas práticas coabitavam na cristandade do Velho Mundo: a do clero e a dos fiéis.

Tratava-se, sobretudo, de um catolicismo piedoso, santoral e festivo, expresso nos exercícios de piedade individual e de comunicação com Deus, quase sempre intermediado por divindades, além da valorização dos aspectos visíveis da fé, através das cerimônias públicas, dos sacramentos,

1 Para Ronaldo VAINFAS (1988), o trabalho dos sacerdotes no Concílio de Trento (1545-63) resultou menos na renovação legislativa da Igreja do que na mudança de atitude em relação aos velhos códigos: nova discussão com respeito à hierarquia eclesiástica, homogeneização da pastoral e da prática sacramental junto às massas de fiéis. Tais questões eram fruto do despreparo e da ineficácia do clero, desde a alta hierarquia aos curas paroquiais. Por isso, a reordenação dos bispados viria acompanhada do estímulo da devoção entre os clérigos, para prepará-los mais adequadamente para o exercício pastoral, numa aproximação mais ampla e profícua entre a Igreja e os leigos, em oposição às práticas cotidianas em que mesmo os grandes momentos da vida, como o batismo, o casamento e a morte, sofriam pouca intervenção do clero e, eram regulados, sobretudo, pelas culturas e tradições locais. 
das novenas, das trezenas, das rezas "fortes", das romarias, das procissões dos santos padroeiros, cheias de alegorias, de que participavam centenas de pessoas, das devoções especiais às almas do purgatório e muitas outras, conforme a região.

Esse perfil sugere que esta religiosidade portuguesa trazida pelos colonizadores não era exatamente marcada por profundas introspecções espirituais uma vez que a maior ênfase recaia nos atos exteriores de culto aos santos, especialmente nos rituais festivos.

Nessa linha de compreensão, Alba Zaluar afirma que as 'festas de santo' que acompanhavam as principais datas e épocas do calendário anual e, toleradas pelos padres, "pouco tinham a ver com a ortodoxia católica apostólica romana (...) valorizavam as práticas cristãs da generosidade e solidariedade 'dos homens de Deus' que promoviam a comensalidade, as danças, a música e os autos das festas santorais” (1994, p. 117).

Assim, dada a forma pela qual as terras brasileiras foram ocupadas, logo prevaleceu um catolicismo marcadamente doméstico, mas igualmente social, que abrangia o chefe familiar, seus agregados e escravos. Nesse contexto, as moradias eram o lócus privilegiado para o exercício da religiosidade privada da população, seja na casa-grande ou nas palhoças dos serviçais.

Normalmente nessas propriedades rurais, próximas à casa-grande, havia a construção de uma capela ou ermida, onde um sacerdote prestava assistência religiosa. Para José Artur Rios essa religiosidade 'latifundiária' e patriarcal era marcada pela vida fechada nas fazendas e nos engenhos, "assentava uma estrutura social que dividia senhores e escravos, patrões e agregados (...) cortada entre o tronco e a senzala, de sadismo e promiscuidade" (1994, p. 24).

Dessa forma, garante Souza (1986), a religiosidade subordinava-se à força aglutinadora dos engenhos de açúcar, integrando o triângulo Casagrande-Senzala-Capela.

José Arthur Rios (1994) lembra, no entanto, que a instrução religiosa dos escravos era mínima. Os sacerdotes limitavam-se a lhes ensinar algumas orações e os rudimentos do catecismo. Os jesuítas se posicionavam contra essa atitude. Defendiam que era obrigação do senhor dar ao seu escravo 
tudo o que conduzia à conservação da vida humana: sustento, vestuário, medicamentos nas enfermidades e, sobretudo, a doutrina cristã através dos sacramentos ${ }^{2}$. Muitos jesuítas em seus sermões, de acordo com Rios, acusavam párocos e senhores de escravos de manterem os cativos na ignorância das coisas de Deus e com isso justificavam o sem-número de malefícios que afligiam o mundo colonial: falta de víveres e mantimentos, e especialmente as doenças.

No mundo rural constituído de propriedades praticamente isoladas, prevaleceu uma vivência religiosa autônoma, bem pouco identificada com a hierarquia eclesial. Portugueses, nativos e africanos podiam expressar livremente as suas tradições religiosas, praticamente sem nenhum controle, como por exemplo, as danças e os fogos nos festejos de São João, as imagens de santos domésticos e, até mesmo, evocar, no caso dos escravos, suas divindades africanas, ainda que sob nomes católicos. ${ }^{3}$

João Antônio Andreoni, mais conhecido como padre Antonil, ao que tudo indica, logo percebeu como era importante, em termos de controle social e ideológico, deixar que os escravos manifestassem sua própria fé, pois afirmava que:

2 Nesse sentido podemos apontar que as Constituições Primeiras do Arcebispado da Bahia, de 1707 , representavam a primeira tentativa de enquadrar a vida cristã na colônia, de acordo com os dispositivos do Direitos Canônico que estabelecia como obrigação de pais, mestres, amos e senhores a ensinar ou fazer ensinar a doutrina cristã aos filhos, discípulos, criados e escravos. No entanto, vale lembrar essa primeira legislação canônica brasileira teve pouca repercussão sobre a vida cristã, na colônia portuguesa, por falta de quem fiscalizasse o cumprimento de suas diretrizes.

3 Dentre as mais conhecidas encontram-se: os ORIXÀS, múltiplas divindades consideradas guias, sendo o maior de todos OXALÁ ou ORIXALÁ, o orixá da criação, representado por Jesus Cristo e Pelo Senhor do Bonfim; OXÓSSI, o orixá dos caçadores, representado por São Jorge e por São Sebastião, portando um arco atravessado de flecha; OXUM, o orixá das águas doces, divindade feminina, deusa da fertilidade, representada por Nossa Senhora das Candeias; OGUM ou OGUNDELÊ, orixá que preside as lutas e as guerras, representação de São Jorge e de Santo Antonio na iconografia católica; XANGÔ, um dos orixás mais poderosos, relacionado com os trovões, o fogo e a justiça, sincretizado, freqüentemente, com São Jerônimo, São Miguel Arcanjo e, algumas vezes, com São João; IANSÂ, divindade feminina, mulher de Xangô, regula os ventos e as tempestades, representada por Santa Bárbara; IEMANJÁ ou JANAÍNA, a mãe d'água ou a rainha do mar, representada Poe Nossa Senhora da Conceição; OMULU, divindade das doenças contagiosas, representada por São Lázaro e São Roque; LOGUN-EDE, orixá dos rios dentro das florestas, sincretizado com São Miguel Arcanjo; OXUMARE, orixá do arco-íris, representado por São Bartolomeu; EXU, orixá que representa as potências contrárias aos homens e, assimilados pelos africanos como o Demônio dos católicos, porém cultuado por eles, que o temem, entre outros (ISTO É, 20.12.2000, p. 97). 
negar-lhes os seus folguetos, que são o único alívio do seu cativeiro é, querê-los desconsolados e melancólicos, de pouca vida e saúde. Portanto, não lhes estranhem os senhores o criarem seus reis, cantar e bailar por algumas horas honestamente em alguns dias do ano e o alegraremse inocentemente à tarde depois de terem feito pela manhã suas festas de Nossa Senhora do Rosário e de São Benedito (1976, p. 161).

Estes festejos, enquanto locais privilegiados para a manifestação de religiosidade popular foram entendidos por João José Reis (1991) como rituais de intercâmbio de energias entre os homens, independentes se livres ou cativos, e as divindades, além de um investimento no futuro, tomando a vida dos devotos mais interessante e segura.

Nessa trilha, Augustin Wernet ressalta que

$O$ caráter social e familiar do catolicismo é percebido na estreita interpretação da religião com a vida social e comunitária. A religião era o núcleo firme de convivência, foi ela que impregnou todas as manifestações da vida social e comunitária. As festas e as manifestações religiosas constituíram uma forma de reunião social, sobretudo nas regiões rurais, de engenhos e fazendas isoladas. O sagrado e o profano andavam unidos e juntos. As procissões e as festas religiosas quebravam a monotonia e a rotina, sendo na maior parte das vezes, uma das poucas oportunidades para o povo se distrair e divertir (1987, p. 24-5).

Maria Clara T. Machado, reforçando o caráter social destas práticas religiosas, enfatiza que a festa, enquanto um ritual religioso, constituía-se em um interregno na labuta diária, dias especiais que fugiam do trivial singularizando a renovação das forças para o recomeçar efetivo, pois "aliavam o sagrado e o profano, a fé e o festar, o calor da oração coletiva e o riso, a música e a dança, as solidariedades e os (re)encontros que, compõe um cenário de esperança por dádivas divinas e o reconhecimento pelas graças recebidas $(2000$, p. 56). 
Como fenômeno urbano, especialmente a partir do início do ciclo minerador no Brasil, esta devoção santoral, a exemplo do que já existia em Portugal, originou as confrarias ${ }^{4}$, divididas em irmandades e ordens terceiras: associações religiosas leigas, que operavam com considerável autonomia, na organização dos cultos religiosos ${ }^{5}$, nas festas dos padroeiros, nas novenas e nas procissões, sobretudo nas regiões desprovidas de sacerdotes. Essa liberdade, no entanto, era limitada, pelo direito canônico, ao controle eclesiástico, além da necessária aprovação, pelo rei português, para a sua criação.

Entre essas associações corporativas, algumas eram poderosíssimas, as da elite branca. Controlavam hospitais, recolhimentos, orfanatos e cemitérios. Sua caridade se realizava da porta para fora, no seu interior, era proibida a entrada dos trabalhadores braçais, quaisquer que fossem eles. As mais significativas, neste contexto, foram as Santas Casas de Misericórdia, as Ordens Terceiras de São Francisco e as Ordens Terceiras do Carmo.

As irmandades religiosas eram regidas por um estatuto interno, denominado de "Compromisso", composto de uma série de artigos que definiam sua origem, o perfil dos "irmãos", além de seus deveres e direitos. Para o cumprimento dessas disposições, essas associações necessitavam de uma receita mínima que cobrisse os custos de manutenção da capela, o

4 Na metrópole, esclarece João José REIS (1991), as primeiras datam do século XIII, dedicandose a obras de caridade, voltadas para seus próprios membros ou para pessoas carentes não associadas. Embora recebessem religiosos, eram formadas, sobretudo por leigos, por isso muitas se associaram a ordens conventuais, como as dos franciscanos, dos dominicanos e das carmelitas. $\mathrm{O}$ autor ainda aponta que para que essas agremiações religiosas funcionassem, era necessário que encontrassem uma igreja que as acolhessem, e que tivessem seu estatuto aprovado pelas autoridades eclesiásticas.

5 A administração de cada confraria ficava a cargo de uma 'mesa', presidida por juízes, provedores ou priores, e se compunha de escrivães, tesoureiros, procuradores e mordomos, que dividiam entre si diversas tarefas, convocação e direção de reuniões, arrecadação de fundos, guarda de livros e bens da confraria, visita de assistência aos irmãos necessitados, organização de funerais, festas, entre outras. A cada ano os confrades se revezavam no exercício destas funções, por meio de votação. Entre os principais deveres dos dirigentes das confrarias, estavam: o bom comportamento, a devoção católica, o pagamento das anuidades e a participação nas cerimônias civis e religiosas da associação. Em troca os irmãos tinham direito à assistência médica e jurídica, socorro em momentos de crise financeira, em alguns casos auxílio para a compra da alforria, além do direito de um enterro decente para si e familiares, com acompanhamento dos confrades e sepultura na capela da associação. 
pagamento do capelão, a assistência funerária aos seus membros e, ainda, a realização de suas festas.

Cabia aos representantes eclesiásticos o controle da vida dessas irmandades, assim, quando entendiam que elas privilegiavam as festas em detrimentos de outros compromissos, eram alertadas para o compromisso estabelecido entre os confrades, especialmente no que se refere à celebração de missas em intenção das almas de seus "irmãos" falecidos. Nesse sentido, não nos parece difícil entender a insistência do clero no cumprimento dos compromissos, de uma forma geral e, em especial, com as missas em intenção dos mortos, mesmo para com as irmandades mais pobres, a de negros forros e mestiços.

Essas associações reforçam os argumentos de Wernet de que o catolicismo brasileiro era o próprio reflexo da organização social vigente, uma vez que elas explicitavam toda a segregação racial da ordem escravocrata. Esta divisão dos cristãos em brancos, negros e mestiços e os primeiros, entre ricos e pobres, contrariava um dos princípios básicos do cristianismo, já que naquele contexto, os homens não eram 'todos irmãos'. Cada um era ‘irmão’ daqueles que fossem da sua raça, da sua classe, da sua condição social, pois a fraternidade, naquele momento, era bastante questionável.

Segundo entendimento de Eduardo Hoornaert, era essa a forma pela qual o povo oprimido recriava com sabedoria instintiva sua religião, refugiando-se nela, como forma de preservar sua identidade. Por isso, as confrarias "morenizaram" o imaginário cristão, "as imagens brancas de olhos azuis trazidas da Europa, foram se tornando morenas com o tempo, ao serem carregadas em andor sobre ombros morenos e beijados por lábios grossos" (1989, p. 96) ${ }^{6}$.

Em uma análise tangencial, Mary Del Priore aponta que essas agremiações religiosas eram uma das poucas formas associativas permitidas à população não branca que as buscavam "não só por razões religiosas, mas porque a participação nelas representava a fuga à marginalização social” (1994, p. 38).

6 Ainda segundo o autor, algumas imagens francamente africanizadas merecem destaque: Nossa Senhora Aparecida (A Virgem Morena do Brasil), São Benedito, Nossa Senhora do Rosário Nossa Senhora de Nazaré (de Belém), entre outros. 
Foi, portanto, na brecha institucional que a irmandade penetrou. Os irmãos de confraria formavam uma alternativa de parentesco. Cabia à "família" de irmãos oferecer a seus membros, além de espaço de comunhão, identidade e socorro nas horas de necessidade, meios de celebrar os santos de devoção, o que representava um investimento ritual no destino após a morte.

Se as irmandades expressavam as desigualdades sociais, no seu interior, ao contrário, todos eram iguais, com os mesmos direitos, constituindo-se assim, num terreno onde podia florescer para a população marginalizada, um sentimento de dignidade, vivenciada, especialmente por ocasião das festas do Divino Espírito Santo, da Folia de Reis, da Procissão das Almas, das Congadas e das Cavalhadas, quando negros, pardos e brancos pobres vestiam belas roupas e "carregavam, pelas ruas, os andores e as cruzes, em procissões coloridas e barulhentas, quase anárquicas, para espanto dos viajantes, que não encontravam aqui o modelo de religião bem ordenada de sua terra" (REZENDE, 1989, p. 91).

A data máxima do calendário de uma confraria era a festa do santo de devoção, pois, segundo Reis (1991), de acordo com a visão barroca do catolicismo, predominante naquele período, o santo não se contentava com a prece individual. Sua intercessão seria mais eficaz, quanto maior a capacidade dos indivíduos de se unirem para homenageá-lo de forma espetacular. Para receber a força do santo, deveriam os devotos fortalecêlo com as festas em seu louvor, ocasião em que se operava o ritual de intercâmbio de energias entre os homens e as divindades.

Assim, a necessidade de abrilhantar essas cerimônias e o interior de suas capelas e igrejas, acabou por revelar muitos artesãos, escultores, pintores e músicos, uma vez que as irmandades rivalizavam entre si no que dizia respeito aos festejos e procissões.

Cabe ressaltar, no entanto, que nem só de festar viviam essas associações religiosas. Sua ação no âmbito caritativo, entre negros e pardos ou ainda entre brancos pobres, muitas vezes era a "única garantia de serem assistidos durante as enfermidades e até mesmo terem um enterro cristão" (HOORNAERT, 1977, p. 383). 
A caridade, assim como a fraternidade, ficava restrita, portanto entre os "irmãos", cabendo a eles a tarefa de amenizar as conseqüências da escravidão e da segregação social.

Todas essas questões levantadas em torno das irmandades, desde as relações estabelecidas no seu interior, como as travadas com o mundo exterior, aparentemente de submissão a regras institucionais, nos sugerem que, muito mais que o destaque dado às festas devocionais, como forma de materializar uma vivência religiosa, era, sobretudo, uma forma de negar seu mundo de cativeiro e de exclusão social.

Ao expressar o colorido das imagens, o movimento das danças e das procissões, o som dos cânticos e dos louvores, os negros e mestiços rompiam com a exploração e a exclusão, a que estavam sujeitos, para recriarem um mundo próprio, distante do mundo dos brancos, onde podiam ser "reis" e "rainhas", pelo menos enquanto duravam os festejos.

\section{REFERÊNCIAS}

ANTONIL, P. Cultura e Opulência do Brasil por suas Drogas e Minas. São Paulo: Melhoramentos, 1976 (edição especial confrontada com a de 1711 e acrescida de notas e comentários).

BURKE, P. Cultura Popular na Idade Moderna. São Paulo: Companhia das Letras, 1989.

DEL PRIORE, M. Religião e Religiosidades no Brasil Colonial. São Paulo: Ática, 1994.

DUBY, G. 0 Historiador Hoje: História e Nova História. Lisboa: Teorema, 1986.

HOORNAERT, E. Formação do Catolicismo Brasileiro (1550-1800). Petrópolis: Vozes, 1977.

- O Cristianismo Moreno no Brasil. Petrópolis: Vozes, 1989.

MACHADO, M. C. T. Pela fé: a representação de tantas histórias. Estudos de História, Franca, v. 7, n. 1, 2000, p. 51-63.

MALDONADO, L. Religiosidades Populares. Concilium, Petrópolis, 
n.206, 1986.

PARKER, C. Religiosidade Popular e Modernização Capitalista: outra lógica na América Latina. Petrópolis: Vozes, 1996.

REIS, J. J. A Morte é uma festa: ritos fúnebres e revolta popular no Brasil do século XIX. São Paulo: Companhia das Letras, 1991.

REZENDE, M. V. Não se pode servir a dois senhores. Lins: Irmãos, 1989.

RIOS, J. A. Sentimento religioso no Brasil. In HORTA, L. P. (Org.) Sagrado e Profano: IX Retrato de um Brasil Fim de Século. Rio de Janeiro: Agir, 1994.

SOUZA, L. De M. E 0 Diabo e a Terra de Santa Cruz. São Paulo: Companhia das Letras, 1986.

VAINFAS, R. Trópicos do pecado: moral, sexualidade e Inquisição no Brasil. Rio de Janeiro: Campus, 1986.

VOVELLE, M. Ideologias e Mentalidades. São Paulo: Brasiliense, 1987.

ZALUAR, A. O Crime e o Diabo na Terra de Deus. In HORTA, L. P. (Org.). Sagrado e Profano: IX Retrato de um Brasil Fim de Século. Rio de Janeiro: Agir, 1994.

WERNET, A. A Igreja Paulista no Século XIX: a reforma de D. Antonio Joaquim de Melo (1851-1861). São Paulo: Ática, 1987. 
